\title{
Article
}

\section{The Effects of In-Home Displays-Revisiting the Context}

\section{Hege Westskog ${ }^{1, *}$, Tanja Winther ${ }^{2}$ and Hanne Sæle ${ }^{3}$}

1 CICERO, Center for International Climate and Environmental Research-Oslo, P.B. 1129 Blindern, N-0318 Oslo, Norway

2 Center for Development and the Environment (SUM), University of Oslo, P.B. 1116 Blindern, N-0317 Oslo, Norway; E-Mail: tanja.winther@sum.uio.no

3 SINTEF Energi AS, P.B. 4761 Sluppen, 7465 Trondheim, Norway; E-Mail: Hanne.Saele@sintef.no

* Author to whom correspondence should be addressed; E-Mail: hege.westskog@cicero.oslo.no; Tel.: +47-9430-7077.

Academic Editors: Panayiota Alevizou, Caroline J. Oates and Seonaidh McDonald

Received: 16 March 2015 / Accepted: 28 April 2015 / Published: 5 May 2015

\begin{abstract}
In this paper, we investigate the extent to which the use of in-home displays affects daily practices and electricity consumption. Through two pilot projects, in-home displays were installed in 33 Norwegian homes, and we provide a qualitative analysis of the effects. The results point to the potential differences in the ways households interact with the in-home displays. The effects differed among various groups according to people's previous experiences with monitoring and their level of affluence. In the sample, affluent respondents living in detached houses tended to be accustomed to monitoring consumption before the display was introduced. These families used the display for controlling that "nothing was wrong", but they did not use the information provided by the display to initiate new energy saving measures. In contrast, among less affluent flat owners the notion of "control" was specifically linked to the family's management of finances, and in this sense the displays empowered them. In addition, the results indicate that the in-home display for this group resulted in electricity savings. The study adds to earlier research on the effects of in-home displays by showing the importance of previous experience with monitoring electricity for the effects of feedback and by highlighting not only energy savings but also social effects of displays.
\end{abstract}

Keywords: in-home displays; electricity; context; affluence; experience; control; energy efficiency 


\section{Introduction}

In the current efforts to obtain a low carbon energy system, new relationships are emerging between mediating technologies and various types of end-users. Smart technologies are being implemented in many countries including Norway, where the rollout of Smart Meter Systems in people's homes is expected to be finalized by 1 January 2019. The EU aims to have smart meters installed in $80 \%$ of households by 2020. Such metering systems do not require action by the user in order for electricity consumption to be measured and registered. In comparison, self-recording is common in Norway today, which implies that the change to automatic metering is likely to make end-users less engaged in recording than today. Moreover, when used in combination with automated payment and billing systems, it is likely that electricity consumption will become even more invisible to end-users than what has usually been the case.

It has been pointed out that apart from when they pay the electricity bill, end-users are rarely concerned with their electricity consumption. Instead people tend to focus on the services made possible by electricity, such as heating, cooking and cleanliness (e.g., [1,2]). Electricity use forms part of home practices which are characterized by routinized behavior often associated with socially conditioned "purposes" [3]. Gram-Hanssen [4] gives the following illustrative example to highlight the challenge for energy conservation policy: "When you are cooking, the goal is to serve a dinner and not to save energy." In the light of these routinized practices where energy is implicated and used for quite different purposes than conservation, the rollout of smart meters and automated payment imply a risk of reducing people's awareness of the links between energy use and resulting consumption, when no other measures are introduced. Electricity will become more invisible.

Nonetheless, the literature indicates that the introduction of direct feedback through in-home displays may be a promising means to compensate for the growing invisibility of electricity. In response to such findings, authorities in some countries such as the UK require that suppliers provide their customers with in-home displays together with the smart meters. The assumptions underlying such initiatives follow the logic of information measures which build on the so-called "information-deficit" model described by Wilhite and Ling [5]: Increased feedback leads to increased awareness or knowledge which induces changes in energy behavior and decreased consumption [6]. The model presumes that customers are motivated to reduce consumption for financial, environmental or other reasons, and that the provision of real-time electricity consumption data will lead to increased awareness or knowledge at the consumer end. Moreover, the model presumes that the new, internalized knowledge will lead to behavioral changes. This approach, rooted in behaviorist models for social change, has been criticized for good reason by many scholars working from a practice theory framework [6-9]. In the present discussion, we seek to combine insights from both practice theory and more behavioristic oriented models when accounting for the effects of displays.

We present findings from a grounded, qualitative study on the use of in-home displays in Norway. Initiated as a research project, 33 families received a display and were later interviewed in their homes. We examine the extent to which the use of displays modified daily practices and affected electricity consumption, as perceived by the respondents. The analysis will disclose that the families differed in terms of how the display affected everyday life, and we contribute this variation to some significant contextual factors. 


\section{The Background Literature}

One of the underlying barriers to electricity savings in households is that electricity is largely an invisible good, which means that it tends to escape human consciousness and reflexivity [10-12]. The fact that most energy use is invisible to the consumer makes it challenging for users to get a clear idea of how much they are using, how their use changes over time, how it relates to meaningful benchmarks, how it is distributed among different purposes, and how it would be affected by different energy-saving measures. However, the use of different types of information measures might mitigate the invisibility of electricity and lead households to more often implement electricity saving measures. As Grønhøj et al. [13] have shown: "Feedback made household electricity consumption more visible and salient, and empowered electricity consumers to take action with respect to lowering their energy consumption."

The literature reveals that various information measures may have different effects on energy savings. Measures referred to as feedback tend to work better with respect to energy savings than to antecedent information [14]. Feedback is a way of making the consequences of behavior more salient, and it may be provided in two forms. Direct feedback is real-time information provided by the electricity meter and displayed on a screen or monitor, referred to as in-home displays, while indirect feedback has been processed in some way before reaching the energy user.

A review by Fischer [15] showed that feedback might result in savings in the range of one to more than $20 \%$, with typical savings in the range of five to $12 \%$. There seems to be a difference in effectiveness between direct and indirect feedback. A review by Darby [16] found that savings from direct feedback normally range from five to $15 \%$, and Fischer [15] concluded that direct feedback studies were overrepresented within "best cases". Recent studies confirm the positive effects of direct feedback on energy savings. Faruqui et al. [17] indicate that consumers who actively use in-home displays reduce their consumption of electricity by about seven percent on average. Savings of electricity of $11 \%-17 \%$ are reported by Gans et al. [18] in their study of real-time usage information in Northern Ireland. Finally, Grønhøj and Thøgersen [13] find that the average electricity savings in Danish households from a display is $8.1 \%$, compared with $0.8 \%$ savings in their control group.

The above mentioned studies point to the general effects of displays without relating the effects of feedback to the socio-economic, material and cultural context in which the technology is implemented. Hargreaves et al. [6] point out that "context is fundamental for understanding the extent to which change effects will be negotiated and realized". For instance, Carlsson-Kanyama and Linden [19] indicate that the users' age and gender influence how they become involved with in-home displays. Murtagh, Gatersleben and Uzzell [20] find a high degree of variation in terms of the use of energy and displays and discuss the role of people's previous experience with energy savings. Schleich et al. [21] analyzed the effects of feedback on electricity consumption in Austria, and found that the effects are dependent on the total electricity consumption of the households. Middle consumption households seem to be more responsive to feedback than households with either low or high levels of consumption. The authors indicate that the reason for this might be that low consumption households already have exhausted their saving potential, while high consuming households are not willing to reduce their consumption because electricity costs constitute a small share of household income. Moreover, studies have found that users have varying degrees of motivation and engagement with the display [22,23]. 
Other studies have also shown how the socio-technical and cultural context might affect energy savings. Winther and Bouly de Lesdain [24] compare the extremely different energy saving cultures that have evolved in France and Norway by providing an analysis that encompasses both the socio-material contexts and people's values and ideas about the good life. Westskog and Winther [25] found that many Norwegian end-users consider electricity to be a common good. This perception is not congruent with the principle underlying the liberal market pricing system, and the mismatch in "logics" reduces people's willingness to engage in energy savings. Finally, Darby [26], focusing on the socio-economic context discusses how smart metering could affect fuel-poor households. She finds that the effects are ambiguous. On the one hand, the restricted access to new technology, know-how and resources might affect the fuel-poor negatively by creating hindrances that prevent them from becoming involved in smart metering technology. On the other hand, the use of smart meters might increase awareness through the potential to develop clear, accurate information by, for instance, deploying energy in-home displays.

The contextual understanding of the effects of in-home displays coincides with an understanding of the uptake of technologies as a socio-technical process in which the interactions between the technology and socially positioned individuals produce the given outcomes. This process is termed "appropriation" (see e.g., [27]), and describes how users integrate technology into their own lives. It is a matter of reciprocity; individuals influence technology and technology influences individuals. On this basis, Wallenborn et al. [27] argue that in-home displays may generally change people's perceptions of electricity, but only households that are already interested or involved in energy savings are willing to use them actively and learn from the display. These perspectives nuance the picture of the effects of in-home displays. To date there has been much research based on behaviorist models of social change with a simple understanding of the relationship between the object and the individual (see Introduction). As Darby [28] indicates, more research on contextual differences is needed to understand the potential effects of in-home displays.

Our study contributes to filling this knowledge gap by focusing on two contextual factors that together influenced the effects of displays: respondents' socio-economic position which affects their motivation for saving and their previous experiences with feedback systems.

\section{The Norwegian Context}

The Norwegian context is peculiar compared to the situation in other countries which have a high proportion of electricity produced by fossil or nuclear sources (e.g., [24]). The high proportion of hydropower production (99\%) makes most Norwegians think of electricity as renewable per se while in reality the electricity system and markets are closely interwoven with countries producing electricity from fossil and nuclear sources. Because electricity in this view is detached from environmental problems, most people do not see the purpose of reducing electricity consumption for environmental reasons. In addition, given the generally high level of affluence in Norway, the two most often noted reasons for people's motivation for saving electricity — reducing costs and environmental concerns - often do not apply. Further, as Westskog and Winther [25] point out, many Norwegians seem to consider electricity to be a common good, not a market commodity. This is due to the high proportion of electricity supplied from hydropower. Historically, hydropower was developed in Norway by building dams and regulating rivers, which many people argue belong to the people of Norway. 
Another distinction between Norway and other countries is the large volume of electricity consumed by residential customers because electricity is commonly used for space and water heating. (Approximately $64 \%$ of the yearly electricity consumption in Norwegian residences is used for space heating and $15 \%$ is used for water heating [29].) The annual, average electricity consumption of households is approximately $16,000 \mathrm{kWh}$ [30]. This relatively high volume indicates that Norwegian households have considerable potential to reduce electricity consumption.

Today Norwegian households have a mechanical meter which they read manually four, six or 12 times per year [31]. The meter value is reported to the electricity utility via web, SMS, mail, etc. A bill is sent to the customer after every reporting period.

In the Norwegian deregulated power system, the distribution system operator (DSO) and the power retailer are two separate entities. This implies that all customers have two separate contracts: one tariff for their use of the grid and one contract for their energy use [32]. Both the network tariff and the energy price are flat in that household consumers pay a given price per $\mathrm{kWh}$ irrespective of their level of consumption, in addition to constant costs. In the planned rollout of smart meters in Norway there is no requirement that in-home displays must be provided to households. The Norwegian regulations only specify that smart meters must provide a standardized interface to accommodate for the use of in-home displays. The regulations require electricity consumption to be metered at least every $60 \mathrm{~min}$, and the meter data must be made available to the customers via a website within 09:00 am the next day. However, it is unclear to what extent end-users will actively access information about their electricity consumption.

\section{Method}

This paper presents the results from two pilot projects in which in-home displays were installed and used in a number of Norwegian households. The displays may be used in combination with both smart and conventional meters. The material is based on in-depth interviews with 33 of these families in their homes. Below we present the selected technologies and recruitment procedures for each of the qualitative experimental trials, before accounting for the process of data collection and analysis.

\subsection{Selection of Technology and Sample, Pilot Project One (eWave)}

The first experimental trial was carried out in the period 2010-2012 in Follo (the eastern part of Norway) and Askøy (the western part of Norway). The participating households were self-recruited through advertisements which focused on the display's capacity to provide consumers with better control of their electricity consumption and bills. The advertisements were published on the grid companies' website and in the local newspapers. Eligible families had to have an annual electricity consumption of at least $20,000 \mathrm{kWh}$, which implied that mainly owners of detached houses participated. This lower limit of 20,000 kWh per year was chosen because the pilot project wanted to focus on customers that had a great potential for energy efficiency. An upper limit of 40,000 kWh per year was also set because the pilot project should not include customers with an abnormally high consumption due to outdoor heating cables, swimming pool, etc. Further, the participants in the test group got the display for free.

A proto-type of the in-home display "eWave" was installed in 91 homes and electricity consumption was registered every second month. However, due to technical problems with the prototype, many 
displays did not function well and the results were not recorded properly. Therefore, the consumption data remains highly uncertain and are not included in this study.

The screen of the eWave display is shown in Figure 1.

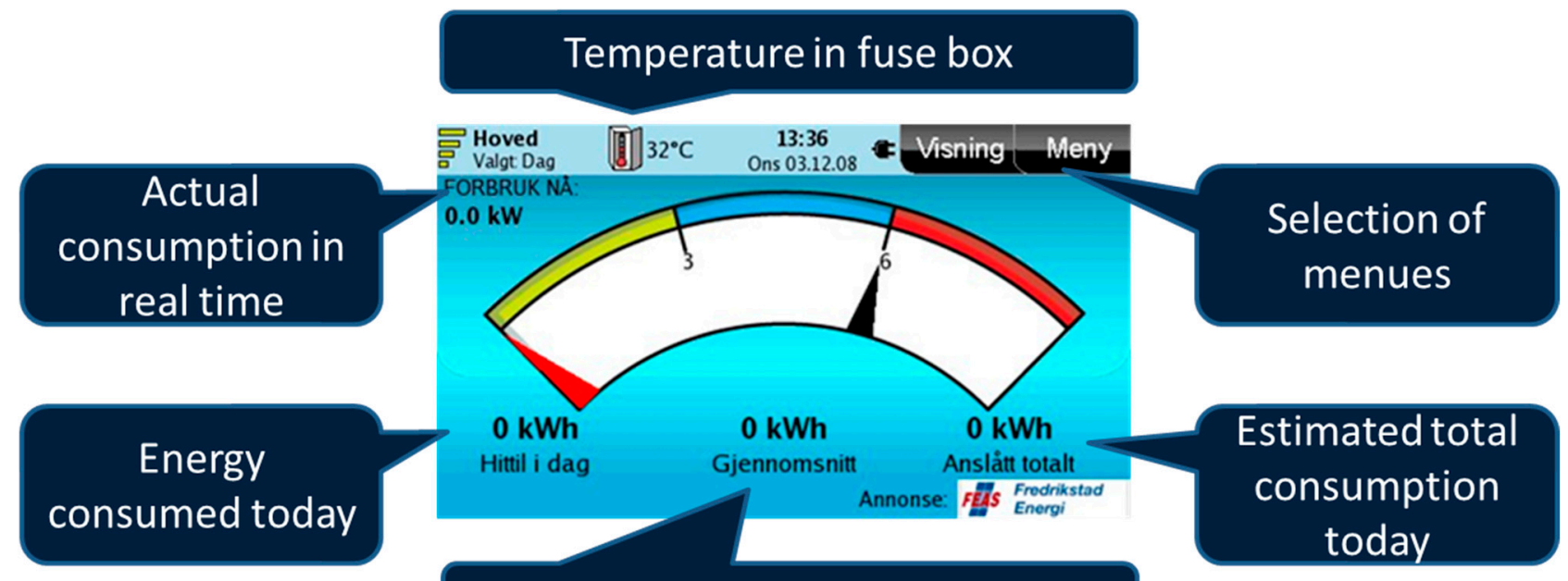

Average consumed energy per day

Figure 1. eWave in-home display.

Three customer surveys were carried out. One survey was carried out before the start-up of the pilot, one three months after the installation and one at the end of the pilot project. The survey results provide important background data for the present study. Approximately $80 \%$ of the test families lived in detached houses whereas $48 \%$ of Norwegian families live in detached houses [30]. When the test families were asked why they had decided to join the study (the categories were pre-defined and respondents could give more than one reason), more than $90 \%$ said it was to obtain better overview and control of electricity consumption, and save costs, $60 \%$ said it was because they were "technically interested", 70\% gave environmental reasons and 35\% said it was to obtain a display for free [33].

To enhance a more detailed understanding of how the proto-type eWave display was used in people's homes and how people perceived the effects of displays on electricity consumption, nine of the test families (five in Askøy and four in Follo) were recruited in 2012 for in-depth interviews which were conducted from one to 1.5 years after the families had received the display. Due to the mentioned technical challenges, two of the families interviewed had problems with the display.

\subsection{Selection of Technology and Sample, Pilot Project Two (Solo II)}

To obtain more families in the qualitative sample we selected another type of display, Solo II. The Solo II in-home display was chosen based on the technology available in the market, price and positive experiences from some Norwegian Distribution System Operators (DSOs). Solo II is produced by Green Energy Options in the UK, and had been on the market for a while, thus it represented a relatively mature technology. For comparative purposes it would have been ideal to have the same display tested in the total sample, but due to the technical problems faced by the first generation of eWave this was not a fruitful path. 
A preliminary analysis of the data from the first pilot (survey and in-depth interviews) indicated that the participants were more affluent than the average Norwegian family (see further details below). Finally, the families in the first pilot were self-recruited through a publicly announced campaign in two municipalities, which increased the possibility of engaging people who were particularly interested in energy consumption [27]. Such sampling bias constitutes a challenge in empirical energy research, and by collaborating with a housing association we aimed to recruit ordinary people in terms of people's level of affluence and interest in energy consumption.

To obtain spread in the total sample we therefore decided to include a number of flats in a housing association in Oslo (Røverkollen) where the Board had a positive attitude towards collaborating and facilitating the recruitment of families. In addition to the above mentioned reasons, this housing association was selected because the flats were heated with electricity (electric resistance ovens), thus we expected the households to have higher electricity consumption (potentially increasing the effect of displays) than what would be the case in housing associations with water carried district heating as their primary heating source. The display Solo II is shown in Figure 2.

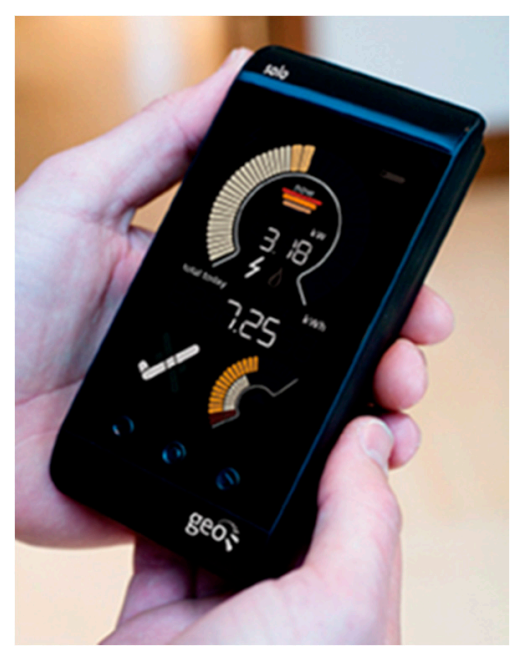

Figure 2. Solo II in-home display.

The building construction in Røverkollen was established in 1974 and consists of five blocks with either four or nine floors, 15 separate entrances with 238 apartments (ranging from two to five rooms in addition to kitchen and bathroom). There are restrictions on energy-related practices in that inhabitants are not allowed to install heat pumps or use certain machines (e.g., washing machines) after eight p.m.

In September 2013, the Board of the Røverkollen housing association sent out a letter to all 125 families living in selected parts of the association, with an invitation to participate in the study to be carried out by the researchers. Seven blocks were included because they had relatively recently had their hot water system changed from individual water heating (running on electricity) to joint metering of hot water consumption. The remaining entities were in the process of changing hot water supply, thus forthcoming changes in consumption due to this change would have been expected during the research period, and they were therefore avoided.

A total of 26 families responded, and shortly after (November 2013) they received a display; 24 of the families were interviewed, from one to three months after installation of the display. Although this study is based on qualitative data obtained through people's own assessments and accounts of changes 
in daily practices, we also measured the participating families' actual electricity consumption before the displays were introduced (October 2013), during the test phase (January 2014), and one year after installation (November 2014). We compared these figures with consumption data of 108 families living in the same blocks who were not included in the study. The association has a joint agreement with an electricity supplier and pays the electricity charges in bulk to the company. Flat owners are billed monthly for a nominal level in advance of consumption, whereupon the balance is issued for payment once a year (February). As mentioned, measuring physical consumption was not an option in the other pilot (eWave) due to poorly functioning displays.

\subsection{Data Collection}

Prior to recruitment, the participating families in the pilot projects were promised that they could keep the test displays as a gift and that those willing to participate in an interview would receive a gift card worth 60 Euros as compensation. The opportunity to obtain a gift card was announced to the families in the Røverkollen housing association as part of the recruitment process to motivate families to participate and reduce the chance that only households with a high interest in technology and energy would join the study. In Follo and Askøy, respondents had already agreed to have a display and had been using it for a while when we asked for interviews and offered a gift card for their participation in an interview.

The eWave and Solo II are similar in that they show real-time consumption through a speedometer dial with different colors as well as accumulated consumption (compared to a set norm) which is displayed in either monetary or technical values. Solo II also visualizes accumulated consumption in the form of a "fuse" which varies in color from green (below norm) to red (above norm). Both types allow users to access their electricity data through the web. The displays communicate wireless and can be used together with conventional meters as well as with smart meters.

The displays are relatively easy to install, but both pilots provided personal assistance during installation, in one case (eWave) through the supplier of the display, and in the other case (Solo II) by a research assistant. The families were given a short explanation of the different functionalities of the display and the families in Røverkollen received a written manual. With input from the family members present, the installer recommended where to place the display. Based on the families' stated monthly consumption in the past, the installer set the norm for electricity consumption. This level, the value either displayed per month or per day, according to the family's preferences, would then be the reference level against which performance (electricity consumption) would be measured. The families received information about how to adjust their reference level, but few reported that they had done so. This means that the reference level was not regularly adjusted according to changes in weather conditions (e.g., summer versus winter) or other reasons for changes in energy use. The users nonetheless seemed to be aware of such causes for changed energy use, and they related and responded to the various types of information offered by the display in a variety of ways, as we elaborate below.

The interview guide included the following topics:

- Family composition and socio-economic background

- About the display - how they used it, how they assessed it and the perceived effects of the in-home display on electricity use

- Interactions with others (family and friends) related to the display 
- Possible reasons for saving electricity

- Views on monitoring, data privacy and security and possible responses to shifting electricity prices during the day

- Electricity and the good life

The interviews were recorded and transcribed. Subjects of importance for the analysis were coded in NVivo (NVivo is a qualitative data analysis computer software package intended to facilitate organizing and analyses of non-numerical or unstructured data). The themes for coding followed the topics of the interview guide. In addition, new themes arose from the material, such as the respondents' childhood family practices related to energy savings, their awareness of energy saving measures from earlier experience with watt meters (see below) and the extent to which they had become aware of the link between the level of electricity consumption and the use of different appliances after receiving the display. In addition, we systematized the data and made profiles of each family in Excel-sheets.

Table 1 shows the main characteristics of the 33 families interviewed, of which nine were included in the first pilot using eWave-living in Follo (F) and Askøy (A) — and 24 families were included in the second pilot using Solo II-living in Røverkollen (R). 33 of the homes were owner occupied and two were tenants (R7, R21). The respondents using eWave were mainly of Norwegian origin, whereas 11 of the families using Solo II had at least one member who had immigrated to Norway (from Asia, Africa and Europe).

Table 1. Characteristics of the sample: Family composition, type of dwelling and gender of respondent. The respondent codes refer to the geographic location of the pilot (eWave: $\mathrm{A}=$ Askøy, F = Follo, Solo II: $\mathrm{R}=$ Røverkollen) and the interview number in the two pilots (pilot 1 with nine interviews and pilot 2 with 24 interviews).

\begin{tabular}{ccl}
\hline Family composition & $\begin{array}{c}\text { Number of } \\
\text { respondents }\end{array}$ & Respondent codes \\
\hline Two or more adults & 8 & A6, F2, R2, R3, R10, R14, R23, R26 \\
\hline Couple with child(ren) & 16 & A7, A8, A10, F1, F4, F5, R5, R7, R9, R11, R13, R15, R17, R18, R21, R25 \\
\hline Single parent & 4 & R1, R4, R8, R12 \\
\hline Single person household & 5 & A9, R6, R19, R22, R24 \\
\hline Income groups & & \\
\hline Financially constrained & 11 & A9, R1, R6, R7, R11, R12, R13, R15, R18, R19, R23 \\
\hline Middle income & 16 & A10, F1, F5, R14, R17, R2, R3, R4, R5, R8, R9, R21, R22, R24, R25, R26 \\
\hline Well off & 6 & A6, A7, A8, F2, F4, R10 \\
\hline Type of dwelling & & \\
\hline Detached house & 7 & A6, A7, A8, A9, A10, F2, F4 \\
\hline Semi-detached & 1 & F5 \\
\hline Flat & 25 & F1, R1-26 \\
\hline Gender of respondents present & & \\
during interview & 9 & A9, R1, R6, R12, R13, R19, R22, R23, R25 \\
\hline Only female & 10 & A8, F1, R2, R4, R5, R8, R10, R15, R21, R24 \\
\hline Only male & 14 & A6, A7, A10, F2, F4, F5, R3, R7, R9, R11, R14, R17, R18, R26 \\
\hline Both female and male & & \\
\hline
\end{tabular}


For reasons of discretion, the two pilot studies did not ask respondents about their level of income, but instead collected banded income data. We base the income categories on the following criteria:

- "Financially constrained" families have one member with low-income employment or they receive social support.

- "Middle income" implies that the family has one or two members with middle-income employment.

- "Well off" implies that the family has at least one member with high-income employment.

To illustrate the monetary value of these income levels, we draw on statistics on the average income levels for various types of occupations in Norway [34,35]. Social support for a single parent with one child: 11,600 Euro, unskilled worker: 43,400 Euro, craftsmen: 50,600 Euro; academic professions: 72,300 Euro, general director: 107,000 Euro. This indicates that the "financially constrained" have an annual household income of less than 40,000 Euro, the "middle income" families make between 50,000 and 100,000 Euro per year and the "well off" families have an annual income above 100,000 Euro. The average income in Norway is 56,230 Euro per person [34].

The table shows that respondents in Røverkollen are more often financially constrained; one household could be characterized as well off, 13 had a middle income and 10 were financially constrained. This would be expected based on the type of housing in which they live; flats tend to be smaller in size and less expensive than detached houses which are common in the other sample. The families interviewed in Askøy and Follo were quite well off; five were well-off, three were in the middle income group and one family was financially constrained according to how we define the income groups (see above). The impression that respondents in Askøy and Follo were relatively affluent corresponds to what was found in the eWave survey which asked respondents to state their level of income and which included these respondents. In the survey, more than half of the participating households had an income larger than 86,200 Euro [33], thus far higher than the average income level in Norway. The registered annual electricity consumption in Røverkollen varied from 7000-18,000 kWh, with $8500 \mathrm{kWh}$ being the most common level, whereas 18,000 kWh was a typical level in Askøy and Follo.

\section{Findings}

We will present the findings from the two pilot projects successively while focusing on the following aspects: (i) respondents' previous experience with and expressed interest in energy savings; (ii) the effects of the display on energy practices and electricity savings; and (iii) the effects of the display on everyday life defined as control over electricity consumption. When analyzing the effects of displays, it is important to take into consideration the different financial positions of the families in the two pilots, which is linked to the sampling processes. The families in Follo/Askøy using eWave were selected through self-recruitment across a large group of consumers, and the families tended to live in larger houses and be relatively well off compared to the Røverkollen sample (see Table 1). The implication of these differences will become clear when we have presented more of the material. 


\subsection{Results from Pilot Project One, eWave}

\subsubsection{Previous Experience and Expressed Interest}

In this sample, nearly all the families expressed a high interest in energy savings and had considerable previous experience with energy saving measures. When asked to rank their level of interest in saving electricity on a scale from one (low interest) to five (high interest), most of them gave a score of five (five families), while one said four, and the rest three. When asked why they wanted to save, they mentioned idealistic motives (altruism/environmentalism) and the perception that it is smart not to waste ("not throw money out of the window"). To some, the display was regarded as a facilitating technology which made savings "fun". Few said that they needed to save to manage their finances, which reflects their relatively high level of affluence.

In addition, reflecting their long experience with electricity monitoring, most of them were familiar with the use of the old watt meters (seven of the families). These meters were installed in many Norwegian homes in the 1970s and 1980s when households became subject to a two-price tariff on electricity, referred to as the $\mathrm{H} 3$ tariff. This metering device shows customers their electricity use (watt) in real time and contains a red arrow at the point where a higher tariff level used to apply (NOU 1998). The watt meter is similar to the speedometer of the in-home displays, showing the household's immediate consumption. Many of the interviewees referred to the watt meter when explaining how they monitor energy use and when describing the role of the new display for their energy practices (six out of nine respondents). Some said that they still use the watt meter actively to check their electricity use (four families). One interviewee explained (F2):

Interviewer: Does the information provided on the display satisfy your need to understand energy consumption? Or do you think you would have understood it anyway?

Interviewee: No, it doesn't provide any extra value compared to our watt meter. The watt meter is very important because let's say we turned a fan heater on two kilowatts in the room downstairs and then forgot about it. We would notice that on the watt meter: What is turned on now? That's the important thing, what is turned on now.

This family also pointed out how the watt meter has made them aware of their electricity use:

Interviewer: So you are saying that the watt meter had an effect in terms of making you conscious about consumption?

Interviewee 1: Yes. We had a watt meter in the place we lived before.

Interviewee 2: Having the watt meter has been useful, to see that arrow, that visible thing.

\subsubsection{Effects of Displays: Few Changes in Practice}

Very few of the families thought that the display had made them save energy and they did not see how the display could help them save more. Five of them pointed this out and said they had already carried out most of the possible electricity saving measures before they got the display. As one of our families pointed out (A7): 
Interviewer: But do you know if you have saved electricity by using the display, in total?

Interviewee 1: I don't think so.

Interviewee 2: No, because it was the measures we made before the arrival of the display that caused the reduction. If we were to save beyond that, it would have been through automatic regulation of the temperature during night time and similar measures.

Or as another of our families expressed (F2):

Interviewer: So to you, the display has not implied a potential for saving?

Interviewee 1: No

Interviewee 2: No.

Interviewer: There is nothing more to gain or save?

Interviewee: No, when the boiler automatically turns itself on when the temperature goes down, and we happen to run the washing machine at the same time, the display doesn't matter. It doesn't make us use more energy. We only use a bit more power for a short while.

Interviewer: So there is nothing that you think you're not aware of, such as forgetting to turn off the lights?

Interviewee 1: No.

Interviewee 2: No.

Two of our families said that the display might have had an effect, but at the same time they emphasized that they had carried out many measures before they got the display and that this reduced the potential for saving electricity with the display. One family said that they did not know if the display could have had an effect, because the winter had been cold last year and it was difficult to compare.

However, one family said that they had saved a lot of electricity after they got the display. They got the display at the same time as when they received a very high electricity bill. This made them very motivated to save electricity. They used the display to learn about their electricity use and switched from electricity to firewood for heating (the husband had access to free firewood in his job). They also changed their bathing routines (A10):

Interviewer: Have you yourself cut down on the number of showers per week?

Interviewee: No, I take a daily shower, I do, but the little ones [small children] do not take a shower on a daily basis. But there are two adults in this household, and we tend to take a shower together in the evening before going to bed, so by that we save a little, in fact. Less hot water and everything. And we did an experiment when receiving this [display]. We measured the time it took to take a shower and compared it with the time it took to fill the bathtub.

Interviewer: How did you manage to measure that?

Interviewee: We turned on the shower and then we both went in, while measuring the time used. Then we turned on the shower in the bathtub using the same shower device, and then we measured how much water ran into the bathtub during the same amount of time we used when we showered. There was so little water in the tub, only one sixth, and then there were two of us taking a shower at the same time. 
This family, who said they had reduced electricity consumption by one third, was one of the few in the Follo/Askøy sample that had limited previous experience with energy saving measures. They were in the middle income group.

\subsubsection{Effects of Displays - Control over Electricity Consumption}

What is clear from all the interviews in Follo and Askøy is the importance placed on visibility of electricity consumption. Respondents emphasized the capacity of the displays (both watt meters and other displays) to visualize their electricity consumption and noted that this was the device's most important feature. For example, one respondent said (A4):

Interviewer: So if you had had automatic recording of consumption now, and no requirement for self-recording and no display, would you be aware of [your own consumption]?

Interviewee: Yes, I had an old device that I could turn on.

Interviewer: A watt meter?

Interviewee: Yes.

Interviewer: So you had kept using that?

Interviewer: Yes, because I'm used to looking at that indicator and seeing how much electricity is consumed. If you wonder, damn, now 5000 kilowatt hours have been used this period, is there something wrong?

And as this quote shows, even for families who think they have not saved electricity because of the display, the device serves as a control factor in their daily electricity use. These families use the display to detect if something is wrong (as A4 above pointed out) or to check if appliances or lights are turned off or not (A6):

Interviewer: If it changes up or down, do you then understand why? For example, if it goes up? You would know why it happens?

Interviewee: Yes, we usually figure it out. Then I think it's a freezer or something else that has turned itself on.

Interviewee: I recall one time when we had forgotten to turn off a heating cable for a week. We thought about it, why are we using so much electricity? Something wasn't right. Then we found that the heating cable should have been turned off.

In sum, the families using eWave said that they had had extensive previous experience with monitoring their electricity use before obtaining the display, and most of them were also very interested in energy savings. In many cases, they pointed to the increased awareness they had gained through their previous experience with a display (the watt meters). The families also considered the new device to be an important tool for monitoring daily consumption and detecting irregularities. However, with the exception of one family who acquired the display after having receiving an unusually high electricity bill and who thereafter made major adjustments, they did not expect to save electricity as a result of using the display. 


\subsection{Results from Pilot Project Two, Solo II}

\subsubsection{Previous Experience and Expressed Interest}

The majority (15) of the families in Røverkollen said that they had wanted to obtain the display in order to learn about their own consumption. A few (3) said that their interest in technical devices had triggered their participation in the pilot project, and two said that their motivation had been to save costs. This indicates that few families expected to save costs when acquiring the display.

Many of the families said that they had tried to save electricity ahead of the installation of display, ranging from turning off lights in unoccupied rooms to replacing inefficient heaters with new ones. A joint refurbishment project had been accomplished five years earlier. The annual electricity bill provides each household with information of total consumption, but apart from this, the families were not accustomed to monitoring consumption. Three respondents mentioned that they recalled using a watt meter in the past, but none of them had such a meter working in their current flat.

Many of these respondents expressed a great interest in saving energy. When accounting for why they want to save, more than half of the sample (13) said they were primarily concerned with reducing costs. Eight of these families were financially constrained. Among the financial constrained families, nearly all were concerned with saving costs, and none of them said that they save for the sport of it or for environmental reasons. This shows that reducing costs is the most common stated rationale for saving electricity among the families in Røverkollen who were interviewed. However, as seen, few of them expected that the display would help them reduce such costs.

\subsubsection{Effects of Displays: Reduced Consumption}

At the point when the display was used for the first time, most of the families started to test the effect on consumption when turning on and off various appliances. In most cases the display was kept in the kitchen or living room, and the families reported watching the display rather frequently. Some people even said that watching the display had become a new habit: "I check the display every time I go to the kitchen to get a glass of water" (R24). In the initial phase most people were surprised to see the consumption of various appliances. Due to the high degree of sensitivity provided by Solo II, even the effects of minor changes such as turning on a 7W light source became visible and observable: "We found that the light in the entrance used much more electricity than the lights in the living room" (R23).

The surprising discoveries made by the families during the initial phase often compelled them to replace former light sources and appliances with new ones:

"We discovered that one lamp was using a lot of electricity, so we replaced it. The kitchen with the stove took a lot, and also the bathroom (heating) cables." (R2)

"I was surprised to see that the fan heater was using a lot of electricity, so I switched to other heating sources." (R7)

"The electric resistance oven was using a lot, so I bought a new one. I will check the labeling next time I buy a new appliance.” (R12)

The many examples of surprises and adjustments people attributed to the initial use of the display indicate that their insight into electricity consumption has increased in the process. In contrast to the 
majority of the families testing eWave, who were accustomed to monitoring consumption ahead of the pilot, the Solo II displays in Røverkollen provided people with new information about the level of consumption caused by various appliances.

Another type of response to the new information provided and conveyed by the display was that it made them adjust certain practices. For example: "When we adjusted the temperature of the bathroom heating cables by only one degree we could see a considerable effect on consumption" (R14). The most common practices that people said they had modified due to the display were cooking, heating, cleaning (frequency of running the washing machine and dishwasher), lights, and turning off the stand-by function of electronic equipment. Two-thirds of the families gave detailed accounts of how they adjusted their electricity use as a consequence of the information provided by the display, and more than half (13) thought that the display had helped them reduce consumption.

The collected consumption data confirm respondents' perceptions that the display has helped them save electricity. Prior to the pilot, the participating families had a slightly higher level of consumption (3\%) compared to their neighbors. During the first two months after installation of the displays (November-December 2013), participating families consumed $12.3 \%$ less than their neighbors: $940 \mathrm{kWh}$ per month compared to $1073 \mathrm{kWh}$ among neighbors. This indicates that the testing phase had the immediate effect of reducing people's electricity use. The sample size is too small to provide statistically significant results, but the development in physically registered consumption data support the participating families' accounts of saving electricity from the display. This tendency also endured: If we look at consumption following the year after installation, the participating families were using $12.2 \%$ less electricity than their neighbors ( $649 \mathrm{kWh}$ per month compared to 739 among neighbors). It is uncertain whether this difference will persist in the years to come, but these findings indicate that the effects of displays on consumption are not only short lived.

\subsubsection{Effects of Displays: Increased Control over Bills}

Some respondents reflected on the increased awareness provided by the display: "Before we were not aware of the consumption of each appliance" (R3). Many continued to check the display and use the information to adjust consumption which they regarded as unnecessary, such as lowering thermostats on the electrical panel heater when the outdoor temperature increased. This way of using the display to monitor appropriate consumption resembles the pattern observed in the eWave sample, where people said that the display gave them control over consumption. In addition, in Røverkollen, many respondents used the notion of "having more control", but in a different sense; due to the increased visibility and transparency provided by the display, they can know in advance what their forthcoming expenses will be and be able to pay their bills. The issue of control is also captured in this dialogue (R3):

Interviewer: If you were to describe why it feels good to know how much [electricity] you have used today, what would you say?

Interviewee 1: That you have been clever.

Interviewer: Yes, and why is that? Can you try to describe that feeling?

Interviewee 2: You have control over your own life. 
Towards the end of the interviews, the respondents were asked what they associate with the good life, whereupon one respondent said that the good life means having the ability to pay one's bills.

A few families (e.g., those who wanted the display for the sport of it) mentioned the importance of the web function. Some knew how to reset the normal level and play with various types of functionalities. This type of user could be perceived as being more "knowledgeable" about the device's technical functionality than those who simply watched the speedometer. For many respondents, however, the speedometer and daily consumption in Norwegian kroner satisfied their need for information and made them feel in control of consumption and forthcoming costs. Nonetheless, most of the families hesitated when asked if they would be willing to purchase a similar display ( $c a .125$ Euros) on the market.

The display's capacity to offer information on performance in various ways seemed to make it attractive to many different groups, matching their particular need for information. Several respondents with relatively limited insight into the technical functionality of the display had significant insight into appliances and their level of consumption. This quote from a financially constrained woman reflects a high level of precision in terms of her understanding of consumption and the way changes are communicated through the display:

"When the speedometer is in that position I know that the electrical panel heater in the bedroom has turned itself on. Oh, there we see that it is going up and down for a while, which means that the temperature is just between 21 and 22 degrees." (R23)

The families using Solo II had not previously monitored their electricity consumption in the detailed manner that was offered by the display. Prior to installation, their expectations for savings had been modest. However, their experience with using the display made most families adjust their daily practices and more than half of them concluded that the display had made them save electricity. In addition, compared to their neighbors, they used less electricity. Their rationale for saving was most often motivated by a concern for keeping costs down and getting control over bills, which is linked to many families' constrained financial situation.

\section{Discussion and Conclusions}

In a study of smart metering, displays and fuel-poor households, Darby [26] finds that the effects are ambiguous. On the one hand, fuel-poor households have limited access to new technology, know-how and resources, and this might affect them negatively by creating hindrances that prevent them from becoming involved in smart metering technology. On the other hand, when smart meters are used in combination with in-home displays that provide clear and accurate information, this may increase people's awareness of their electricity use and empower fuel-poor households. Darby's study points to the importance of examining the socio-economic context when studying and projecting the effects of displays.

The study presented here contributes to the understanding of how contextual factors such as people's affluence and previous experience might influence the effects of information measures. The project looked at two fairly similar technologies for monitoring electricity consumption which were introduced in households with various levels of affluence and previous experience with monitoring consumption. Our data allow for recognition of potential differences in the way various types of households interact 
with the in-home displays. The affluent respondents living in detached houses tended to be accustomed to monitoring consumption before the display was introduced. Nevertheless, they appreciated the way the new display monitored consumption, and after one and a half years in operation, most of the families continued to keep the device in a central place and watch it regularly. They let it report on irregularities and remind them to adjust various electricity consuming items, and in this way it provided them with control over consumption. These families had a clear picture of the baseline [6], that is, their normal or usual level of consumption. In short, families accustomed to monitoring their consumption used the display for controlling that nothing was wrong. They did not think they had reduced consumption due to the display and they did not use the information provided by the display to initiate new energy saving measures. This was because the potential for savings was already tapped when the display was introduced. Due to the limited sample size, we are not in a position to identify the relative significance of affluence versus previous experience. However, in our previous empirical work in Norway in which we studied people's attitudes towards energy savings [25,36], relatively well-off respondents tended to show limited interest in energy saving measures. Therefore, our impression is that the most important feature of the "eWave" sample is people's keen interest in and experience with monitoring, which makes them a rather untypical sample of the Norwegian population, regardless of wealth category.

Among the less affluent flat owners, the notion of "control" was also commonly referred to, but in these cases, being "in control" was specifically linked to the family's management of finances. They felt the display provided important information which would prepare them for the next bill. Instead of waiting for the yearly balance, which could either be a pleasant surprise or a major problem (high bill), they felt they were in control when they received continuous information about performance and how much money they would spend. This finding partly contradicts the conclusions from the study by Hargreaves and colleagues [6] who found that some of the financially constrained UK customers became disempowered from using the display. When poor UK households observed the specific monetary value associated with various types of consumption, this would create anxiety and frustration for them. In the present study from Norway, one of the central findings is that people, in particular those with financial constraints, appreciated the detailed information which gave them control over their finances, and in this sense the displays empowered them. An explanatory factor for the difference between the UK and Norway might be that the Norwegian families who are defined in this study as "financially constrained" might have been less materially deprived than the poorest UK families.

Regardless of their financial capacity, all the flat dwellers had gone through a specific process of learning which had the following sequence. First, they tested out and learned about the consumption of individual appliances, which often triggered a comparison between various appliances and how much they consumed. This confirms the monitor's potential for making energy-use visible and "relational" [6]. Second, the testing phase resulted in various kinds of responses (behavioral changes). Appliances and heating devices which consumed more than what they considered to be normal were replaced with new ones. With regard to future purchases, respondents said they would look for electrical appliances labelled as energy efficient. Hence the display affected people's investments in energy saving measures. Furthermore, the display motivated people to make reductions. The families modified their daily consumption patterns (habits) in various ways, especially with regard to cooking, heating and lighting. In comparison, the families who were already experienced with monitoring consumption had gone through this learning process before the display arrived, which is the main reason they thought the display had not affected 
their electricity use. In contrast, most of the flat owners expressed the expectation that the completed adjustments had led to reduced consumption. This perception was supported by the physical measurement. It is interesting to see that these evaluations of effects largely contrast with their stated rationale for joining the pilot project, which was mainly to "learn about" their own electricity consumption.

Much of the research on the effects of information measures such as direct feedback mechanisms and in-home displays presupposes that through conscious or reflexive processes and increased knowledge people will change their behavior based on the information provided. However, as critiques of this information-deficit model have argued [5,6,20], information measures and their projected effects need to be considered within the socio-cultural and material context in which they are implemented. Our results show that the information-deficit model had considerable relevance in the case of low income households without previous monitoring experience. We argue that the reason why the observed dynamics in this case fitted with the model was, firstly, that the users were in fact concerned about their costs and were motivated to reduce them. Secondly, their lack of previous experience with electricity monitoring implied that they considered the information to be useful for understanding and thereafter potentially reducing consumption. The users perceived the information to be clear and the feedback was immediate and user-specific, which observers point out is a criteria for success [16]. To the other group of households, the information-deficit model was clearly not relevant. This was partly because people were already accustomed to monitoring consumption, thus they already had access to the knowledge provided by the display. In addition, due to their higher level of affluence, they were not compelled to focus on savings. Our results confirm the findings of Schleich et al. [21] that the effects of displays differ across household groups and the degree of affluence. We nuance these results by also showing the importance of previous experience with monitoring of electricity for the effects of feedback.

Related to the ignorance of the differences across household groups, the information-deficit model might both overestimate and reduce the potential effects of in-home displays. One risks overestimating the effects of displays on energy consumption by generalizing the effects across household groups. Other factors which are not explored in the present discussion are likely to come into play, such as the type of building and the regulations that apply (e.g., for detached houses versus flats) and other material aspects (e.g., type of heating device).At the same time, because the model is focused on energy savings only, other effects such as learning and control of finances (and life), are overlooked. Correspondingly, the value of these side effects is underestimated.

This study has pointed to potential differences between various types of households in their interactions with in-home displays. For less advantageous groups without previous monitoring experience, the display can provide social benefits and energy savings at the same time. According to Norwegian regulations, households are not required to be provided with in-home displays in the planned rollout of smart meters. Instead, the authorities expect that the introduction of smart meters will enhance the development and promotion of feedback solutions offered by commercial actors. Our study indicates that groups who could benefit substantially from using displays will not be willing to invest in them. This policy might therefore lead to increased invisibility of electricity consumption, less control over consumption, reduced potential for electricity savings and increased differences across socio-economic groups. Hence, we might see a situation where those already interested in monitoring electricity consumption purchase in-home displays or access information about the electricity consumption through web pages or other sources, while for the ordinary non-engaged customer electricity ends up being a 
completely invisible good. In the UK, energy suppliers are required to provide their customers with in-home displays together with the smart meters. Based on the findings from this study, consideration should be given to implementing this policy elsewhere.

\section{Acknowledgments}

This research derives from the project "Energy savings from regulation to realization" (ESPARR), financed by the Research Council of Norway (2012-2015), project No. 216473/E20. The "Solo II" pilot also received funding from CREE-Oslo Center for Research on Environmentally Friendly Energy, which is financed by the Research Council of Norway, project No. 209698/E20. One of the authors is associated with CREE. The "eWave" pilot was a collaboration between a research project at SINTEF Energy Research called "Environmental benefits from large scale establishment of smart meters" (2009-2013) and the ESPARR project.

\section{Author Contributions}

Westskog and Winther designed and conducted the qualitative research and analyzed the results. Sæle conducted and analyzed the survey data. All authors contributed to writing the paper, and read and approved the final manuscript.

\section{Conflicts of Interest}

The authors declare no conflict of interest.

\section{References}

1. Wilhite, H.; Nakagami, H.; Masuda, T.; Yamada, Y.; Haneda, H. A cross-cultural analysis of household energy-use behavior in Japan and Norway. In Consumption: Critical Concepts in the Social Sciences; Miller, D., Ed.; Routledge: London, UK, 2001; pp. 159-177.

2. Shove, E. Comfort, Cleanliness and Convenience: The Social Organization of Normality; Berg: Oxford, UK; New York, NY, USA, 2003.

3. Ortner, S.B. Anthropology and Social Theory: Culture, Power, and the Acting Subject; Duke University Press: Durham, NC, USA, 2006.

4. Gram-Hanssen, K. New needs for better understanding of household's energy consumption-Behaviour, lifestyle or practices? Archit. Eng. Des. Manag. 2014, 10, 91-107.

5. Wilhite, H.; Ling, R. Measured energy savings from a more informative energy bill. Energy Build. 1995, 22, 145-155.

6. Hargreaves, T.; Nye, M.; Burgess, J. Making energy visible: A qualitative field study of how householders interact with feedback from smart energy monitors. Energy Policy 2010, 38, 6111-6119.

7. Wilhite, H. Anthropological perspectives on practice theory and efforts to reduce energy consumption. Practice theory and climate change. In Proceedings of the Lancaster University Workshop Conference, Lancaster, UK, 6-7 July 2010; pp. 1-16.

8. Sahakian, M.; Wilhite, H. Making practice theory practicable: Towards more sustainable forms of consumption. J. Consum. Cult. 2014, 14, 25-44. 
9. Shove, E. Beyond the ABC: Climate change policy and theories of social change. Environ. Plan. A 2010, 42, 1273-1285.

10. Lindén, A.L.; Carlsson-Kanyama, A.; Eriksson, B. Efficient and inefficient aspects of residential energy behaviour: What are the policy instruments for change? Energy Policy 2006, 34, 1918-1927.

11. Pedersen, L.H. The Dynamics of Green Consumption: A Matter of Visibility? J. Environ. Policy Plan. 2000, 2, 193-210.

12. Burgess, J.; Nye, M. Rematerialising energy use through transparent monitoring systems. Energy Policy 2008, 36, 4454-4459.

13. Grønhøj, A.; Thøgersen, J. Feedback on household electricity consumption: Learning and social influence processes. Int. J. Consum. Stud. 2011, 35, 138-145.

14. Abrahamse, W.; Steg, L.; Vlek, C.; Rothengatter, T. A review of intervention studies aimed at household energy conservation. J. Environ. Psychol. 2005, 25, 273-291.

15. Fischer, C. Feedback on household electricity consumption: A tool for saving energy? Energy Effic. 2008, 1, 79-104.

16. Darby, S. The Effectiveness of Feedback on Energy Consumption. A Review for DEFRA of the Literature on Metering, Billing and Direct Displays; Oxford University: Oxford, UK, 2006. Available online: http://www.eci.ox.ac.uk/research/energy/downloads/smart-metering-report.pdf (accessed on 3 March 2015).

17. Faruqui, A.; Sergici, S.; Sharif, A. The impact of informational feedback on energy consumption-A survey of the experimental evidence. Energy 2010, 35, 1598-1608.

18. Gans, W.; Alberini, A.; Longo, A. Smart meter devices and the effect of feedback on residential electricity consumption: Evidence from a natural experiment in Northern Ireland. Energy Econ. 2013, 36, 729-743.

19. Carlsson-Kanyama, A.; Lindén, A.L. Energy efficiency in residences-Challenges for women and men in the North. Energy Policy 2007, 35, 2163-2172.

20. Murtagh, N.; Gatersleben, B.; Uzzell, D. 20:60:20_Differences in energy behaviour and conservation between and within households with electricity monitors. PLOS ONE 2014, 9, e92019, Available online: http://www.ploscollections.org/article/fetchObject.action?uri=info\%3Adoi\% 2F10.1371\%2Fjournal.pone.0092019\&representation=PDF (accessed on 10 April 2015).

21. Schleich, J.; Klobasa, M.; Gölz, S.; Brunner, M. Effects of feedback on residential electricity demand-Findings from a field trial in Austria. Energy Policy 2013, 61, 1097-1106.

22. Oltra, C.; Boso, A.; Espluga, J.; Prades, A. A qualitative study of users' engagement with real-time feedback from in-house energy consumption displays. Energy Policy 2013, 61, 788-792.

23. Buchanan, K.; Russo, R.; Anderson, B. The question of energy reduction: The problem(s) with feedback. Energy Policy 2015, 77, 89-96.

24. Winther, T.; Bouly de Lesdain, S. Electricity, uncertainty and the good life: A comparison of French and Norwegian household responses to policy appeals for sustainable energy. Energy Environ. Res. 2013, 3, 71-84.

25. Westskog, H.; Winther, T. Electricity consumption: Should there be a limit? Implications of people's attitudes for the forming of sustainable energy policies. Cons. J. Sustain. Dev. 2014, 11, $97-114$. 
26. Darby, S. Metering: EU policy and implications for fuel poor households. Energy Policy 2012, 49, 98-106.

27. Wallenborn, G.; Orsini, M.; Vanhaverbeke, J. Household appropriation of electricity monitors. Int. J. Consum. Stud. 2011, 35, 146-152.

28. Darby, S. Smart metering: What potential for householder engagement? Build. Res. Inf. 2010, 38, 442-457.

29. Grinden, B.; Feilberg, N. Analysis of Monitoring Campaign in Europe; ISR-University of Coimbra: Coimbra, Portugal, 2008. Available online: http://remodece.isr.uc.pt/downloads/REMODECE_D10_ Nov2008_Final.pdf (accessed on 17 January 2015).

30. Statistics Norway. Energibruk i Husholdningene, 2012; Statistics Norway: Oslo, Norway, 2012. Available online: http://www.ssb.no/energi-og-industri/statistikker/husenergi (accessed on 12 April 2015).

31. Lovdata. Forskrift om Måling, Avregning og Samordnet Opptreden ved Kraftomsetning og Fakturering $a v$ Nettjenester; Norwegian Ministry of Oil and Energy: Oslo, Norway, 1999. (In Norwegian)

32. Sæle, H.; Grande, O.S. Demand response from household customers: Experiences from a pilot study in Norway. IEEE Trans. Smart Grid 2011, 2, 102-109.

33. Sæle, H.; Sagosen, Ø. Erfaringer og Oversikt over Kundedisplay. Resultater fra Uttesting av Kundedisplayet eWave; SINTEF Energi AS, 2014-05-27, TR A7358; SINTEF Energi: Trondheim, Norway, 2014. (In Norwegian)

34. Statistics Norway. Earnings of All Employees, 2013; Statistics Norway: Oslo, Norway, 2014. Available online: http://www.ssb.no/en/arbeid-og-lonn/statistikker/lonnansatt/aar/2014-03-20 (accessed on 26 January 2015).

35. Regjeringen. Rundskriv A-1/2014-Statlige Veiledende Retningslinjer for Økonomisk Stønad 2015. Available online: https://www.regjeringen.no/nb/dokumenter/rundskriv-a-12014---statligeveiledende-retningslinjer-for-okonomisk-stonad-2015/id2356559/ (accessed on 20 April 2015).

36. Winther, T.; Ericson, T. Matching policy and people? Household responses to the promotion of renewable electricity. Energy Effic. 2013, 6, 369-385.

(C) 2015 by the authors; licensee MDPI, Basel, Switzerland. This article is an open access article distributed under the terms and conditions of the Creative Commons Attribution license (http://creativecommons.org/licenses/by/4.0/). 